An identical conclusion was reached by Giesecke et al. (Nucleic Acids Res. $4,3943 ; 1977)$ in their bid to detect the in vitro synthesis of ovalbumin in RNA sequences from chick oviduct chromatin with $E$. coli polymerase.

These reports are somewhat alarming since they would imply that no DNAdependent gene-specific transcription can be detected in chromatin in which these genes are known to be active in vivo. How would this conclusion affect the interpretation of the vast bulk of chromatin transcription data accumulated over the past decade or so? Several comments spring to mind.

Before cDNA was available, chromatin transcripts were analysed qualitatively by hybridising purified in vitro labelled transcripts to denatured total DNA bound to nitrocellulose filters. The amount of label converted into RNase-resistant hybrid gave an estimate of sequence homology. In this analysis, transcription of endogenous RNA would give rise to a labelled copy which would hybridise to DNA in the same way as if correct DNA transcription had taken place except that the strand sense is reversed.

Gene-specific cDNAs have been made from ovalbumin, histone and a variety of globin messenger RNAs and used as hybridisation probes for chromatin transcripts. As already pointed out the data obtained are only valid where it can be shown that endogenous RNA sequences are not interfering with the analysis. Where this is so and it has not been considered necessary to resort to mercurated nucleotides it is difficult to see how gene-specific transcripts can arise other than by direct transcription of the DNA itself. However, a number of workers have indeed used the mercury technique, suggesting that endogenous RNA is a problem with chromatin in general. In this case the criticism of Zasloff and Felsenfeld is a valid one and unless steps are taken to avoid cross-contamination of transcripts with endogenous RNA the data cannot be sidered conclusive.

Attempts have been made to assess the fidelity of transcription from chromatin with respect to DNA strand selection by bacterial and isolated animal polymerases. In many cases where symmetrical transcription is seen this has been interpreted in terms of loss of enzyme specificity in in vitro conditions. However, endogenous RNA transcription rather than non-selective DNA strand copying might equally well account for the findings.

It should be mentioned that the strongest evidence for RNA copying presented by Zasloff and Felsenfeld and Giesecke et al. comes from experiments where purified mRNA is added to

\title{
The blind fishes of Persia
}

IT was exciting to read the note by G. Thines in News and Views (271, 305 ; 1978) which affirmed his 'great interest' in the discovery of two cavernicolous forms in the same welllike outlet. However, it is possible that a misunderstanding has occurred which needs to be corrected. The fish were indeed both found in the same well-like outlet; but this resurgence, which did resemble a well, was an entirely natural event. As much of the note's argument concerned the coexistence of cave forms in biotopes other than those of caves it is important to clarify the actual situation.

The two fish species were Iranocypris typhlops (Cyprinidae), first described by Bruun and Kaiser in Dan. scient. Invest. Iran 4, 1-8 (1943, published 1950), and Noemacheilus smithi (Cobitidae), first described by P. H. Greenwood in J. Zool. (180, 129; 1976). The Danish paper, which also gives a photograph of the discovered location of $I$. typhlops, mentions that 'the water comes from the subterranean source in the background' of the picture. I discovered $N$. smithi by going to this precise spot and observing the blind loach in the same pool as the previously discovered blind carp. In his paper Greenwood confirms the Danish description and stresses the naturalness of this resurgence: 'There, exactly as described by Bruun \& Kaiser, [Smith] found a small group of fishes swimming in the well-like outlet of a subterranean water-body. Since the habitat is fully exposed to light and in no way resembles a cave, it seems reasonable to suppose that the typically cavernicolous fishes living there are accidental strays from a true cave environment within the mountains.'

The case of 1. typhlops coexisting with $N$. smithi is not similar to that of Milyeringa veritas and Anommatophasma candidum, or the other examples quoted by Thinès. Both $N$. smithi and $I$. typhlops have so far been found in only a single locality and that locality is neither a well nor an artificial outlet. It cannot be argued that their case is 'a typical instance of an already well-known

transcription systems. However, it is probable that endogenous RNA does not exist in this free form and may be tightly bound within the chromatin structure. While it is not known whether this RNA can be copied by RNA polymerase, any cytoplasmic mRNA contaminating the chromatin might well produce an artefact. The levels of cytoplasmic globin and oval- phenomenon, whose meaning for biospeleological research is clear.'

What is still completely unclear is the nature of the true habitat of the blind fishes of Persia, so far discovered only in a single resurgence near Tang-e-Haft in the Zagros mountains. An attempt was made in 1977 by two caving experts equipped with breathing apparatus to gain access to the cave system. Greenwood and others considered that the "welllike outlet' could not possibly be the sole habitat of the two Persian fishes. During the snow-melt period of spring this outlet always overflows to form a small stream, according to local villagers, but in May or June the overflow ceases. For the rest of each year the well of water has a surface area approximately $5 \mathrm{~m}$ by $3 \mathrm{~m}$ and this gradually decreases as the season progresses.

The two divers attempted their exploration in April when the outlet was no longer overflowing, it being an exceptionally dry year, and they descended to a depth of about $20 \mathrm{~m}$. Right from the surface the resurgence narrowed until it became impossible for the men to progress further. Their opinion was that 'a major dry system did not necessarily exist within the mountain' and that 'a vast volume of water could be contained in a massive underground maze of flooded rifts' (personal communication). They thought it unlikely that anyone would find a way in to the real habitat of the Persian cave fishes as the nearby mountains "were composed of limestone with very thin beddings, varying from 15 to $60 \mathrm{cms}$, which were almost vertical. Not only was the rock very friable, making major cave systems improbable, but any caves which did exist were likely to be high narrow rifts.' It would seem that, for the time being, the blind cave fishes of Persia are quite safe within their cave, save for the few of their number who stray inadvertently into a resurgence where they are (very occasionally) caught by passing naturalists.

ANTHONY SMITH

9 Steele's Road,

London NW3

bumin mRNAs in these systems are extremely high and therefore it is still not clear whether the observations are due to an intrinsic feature of the chromatin structure or inadvertent cytoplasmic contamination. Whatever the answer, the impact of these findings should encourage workers in this field to examine their own particular systems with ruthless scrutiny. 